Maladies of Hevea in Malaya

By Roger N. Hilton. With watercolours by Hoh Choo Chuan. Pp. 101. (Kuala Lumpur: Rubber Research Institute of Malaya, 1959.) 30 Malayan dollars.

THE reviewer feels he should make it clear at the outset that his acquaintance with Hevea brasiliensis as a plantation tree is limited to Trinidad, where the climate is not wholly suited to it and where it is accordingly little grown. He has therefore no personal experience of the diseases as such, though many of the fungi figured are familiar in other contexts. With these limitations he feels it difficult to criticize Mr. Hilton's text. Mr. Hoh Choo Chuan's watercolours are outstanding no less for their beauty than for their extraordinary faithfulness and precision while their reproduction is of the highest quality. Anyone who has tried to record white hyphæ and mycelial strands straying over living leaves will appreciate the skill displayed in, for example, the plates of thread blight and powdery mildew.

Only diseases and injuries to Hevea already known in Malaya are figured. These include fasciation, leaf malformation, genetic yellows, chlorosis, oil spot, leaf rim blight, sun scorch, heat scorch, lightning damage, fire damage, symptoms of herbicide poisoning, waterlogging and drought, brown bast, fissures of the tapping panel and bark burrs as well as troubles associated with fungi and with Loranthus spp. Each plate is accompanied by a page of text on which information regarding the disease is summarized under the headings: symptoms, cause, other hosts and spread (where a pathogen is involved), prevention and treatment. The diseases are arranged under the following headings : those affecting the whole plant, the roots, the stem and branches, the tapping panel, leaves of young plants and leaves of mature plants. The point of view is severely practical throughout and the work should prove a valuable handbook to the rubber planter in the eastern tropics.

$$
\text { R. W. G. DennNis }
$$

\section{Theory of Beams}

The Application of the Laplace Transformation Methods to Engineering Problems. By T. Iwinski. Translated from the Polish by E. P. Bernat. Pp. 85 . (London and New York: Pergamon Press, 1958.) 21s. net.

FROM the point of view of the structural engineer with mathematical inclinations this is an interesting little book and it is likely to be stimulating to advanced students. The solution of beam problems in practice has, however, long since been reduced to the judicious use of tabulated information and most problems can be dealt with rapidly in this way.

It is stated that this monograph is the first part of a major project on the application of the Laplace transformation method to problems in the theory of structures. Solution of the differential equation of uniform beams with linear elasticity and uniform loading by means of the Laplace transformation is demonstrated followed by generalization to include the effects of concentrated forces and couples. It is shown that the solution always consists of two parts: one part depends upon the support or boundary conditions while the other depends upon the system of loading. By taking account of this feature it is shown that the problem of determining the deflected form of a beam can be transformed from the solution of a differential equation to the solution of simultaneous algebraic equations. Finally, the solution of the differential equation of beams with variable flexural rigidity and subjected to general conditions of loading is considered.

T. M. Charlton

\section{Potassium Symposium 1957}

Sixteen Papers read at the Fourth Congress of the International Potash Institute, Vienna, 1957. Pp. $420+4$ plates. (Berne: International Potash Institute, 1959.) n.p.

HE report published by the International Potash Institute as an outcome of its congresses, held annually from 1953 to 1956 , covered many aspects of broad and general interest, potassium being considered from the aspect of agricultural chemistry throughout the various phases of the plant-soil system. The theme of the last congress is more particularized and the main interest is in a varied assortment of species in close association, especially herbage plants. The part played by potassium in the growth of herbage plants, legumes and grasses, is a complicated matter since numerous factors are involved. The importance of grassland in agriculture justifies such a restricted interest and the papers cover some important aspects of it. One of the topics was the influence of potassium fertilizers on animal production from pasture, another on their influence on the cultivation of irrigated prairies in Italy, and others on their application under widely differing external conditions of moisture and temperature. These titles indicate the general field of interest in the congress. The paper on the production of animals and pasture grazing led to a lively discussion on grass tetany.

This volume, it will be seen, is mainly of agronomic interest and in its field it provides information of real value. The papers are in English, French, German and Italian, in some cases full translations being provided, and in most cases summaries in English, German, French and Italian. It is lavishly produced on thick glossy paper and has illustrations, some in colour, with an author index and subject indexes in English, German, French and Italian.

\section{The Cellular Slime Molds}

By Prof. John Tyler Bonner. (Investigations in the Biological Sciences, No. 1.) Pp. viii $+\mathbf{1 5 0}+8$ plates. (Princeton, N.J.: Princeton University Press; London: Oxford University Press, 1959.) 32s. net.

$D$ RECFDED by a brief review of the Mycetozoa, this account of the Acrasiales, taking in all published work up to 1959 , is divided into three sections corresponding to the biology, morphogenesis and genetics of this group. Although many of the facts and concepts are already available in review form, this new synthesis should be useful to those who have to lecture on these topics and to those wanting a source book on developmental problems in relatively simple organisms. Described on the cover as a monograph, the book lacks the objectivity and balance that is looked for in this form of writing, particularly in respect of the varying emphasis given to different aspects of our knowledge, and in the conjectural nature of much of the discussion. It is towards the end of the book (p. 133) that the author realizes "such speculation soon becomes hollow and unrewarding".
D. PARK 